\title{
Factors influencing condom use in a sample of homosexually active men
}

\author{
Ray Fitzpatrick, John McLean, Jill Dawson, Mary Boulton, Graham Hart
}

\begin{abstract}
A sample of 502 homosexually active men were recruited from genitourinary medicine clinics and non clinic sources and interviewed in relation to their sexual behaviour and factors that might influence their use of condoms. Three hundred and eighty three men (76\%) reported penetrative anal sex in the previous year. Ninety four $(25 \%)$ had not used condoms in penetrative sex. Failure to use condoms was associated with unfavourable attitudes to them, not knowing close friends or partners who had HIV-related health problems, having fewer sexual partners and being in a closed monogamous relationship. On the other hand levels of awareness about the risks of unprotected anal sex and involvement in gay networks and social groups were not predictors of condom use.
\end{abstract}

\section{Introduction \\ Homosexually active men constitute the largest group of AIDS cases and of individuals reported as seropositive for HIV in England. Recent clinic-based studies have suggested that rates of HIV infection may have stabilised in this group..$^{1-3}$ Rates of sexually transmitted diseases amongst homosexually active men have declined. ${ }^{34}$ These trends are consistent with evidence that sexual behaviour has changed both in England and in the United States. ${ }^{5}$ However there is still considerable variability in homosexual sexual behaviour. ${ }^{6}$ In particular, there is evidence that, in both England ${ }^{7}$ and the United States, ${ }^{8}$ a substantial number of homosexually active men do not use condoms in penetrative anal sex.}

Department of Public Health and Primary Care, University of Oxford

Ray Fitzpatrick, Jill Dawson

Academic Department of Community Medicine, St Mary's Hospital, London

John McLean

Mary Boulton

Academic Department of Genito-Urinary Medicine, University College and Middlesex School of Medicine, London, UK

Graham Hart
This paper reports condom use in a sample of homosexually active men recruited from both clinic and non clinic sources, and examines attitudes and other variables that may be associated with patterns of use. Variables were selected with reference to the Health Belief Model (HBM), initially developed to explain the adoption of appropriate behaviours (such as attendance for screening) in other areas of health care, ${ }^{9}$ and more recently employed to investigate variations in behaviour in relation to AIDS. ${ }^{10}$ Four particular areas of the HBM were examined for possible effects upon use of condoms: (1) positive and negative attitudes towards condoms (2) perceived vulnerability to HIV infection (arising from the occurrence of AIDS-related problems amongst close friends or involvement in more active sexual lifestyle) (3) social network variables (for example involvement in gay groups and organisations) and (4) knowledge about health risks.

\section{Methods and sample}

The criterion for inclusion in this study was any man who had had sexual contact with another man within the last five years. A sample of 502 men was recruited from a diverse range of sources: $283(56 \%)$ from gay pubs, clubs and gay organisations; $96(19 \%)$ by referrals from those already interviewed ("snowball" sampling) and $123(25 \%)$ from departments of genito-urinary medicine. Four main towns and cities were used: London 228 (45\%), Manchester 145 $\left(29^{\circ}\right)$ ), Oxford $65(13 \%)$ and Northampton $31(6 \%)$. A further $33(7 \%)$ of the sample were recruited from areas around these four centres. Interviews were conducted throughout 1988 and from January to July 1989.

Interviews focused on sexual behaviour in the previous month and previous year. The reliability ${ }^{11}$ and validity ${ }^{12}$ of self reported homosexual sexual behaviour in interviews covering such short periods of recall has been established. Information was gathered by means of a check list of sexual behaviours, and so far as possible, respondents were asked to describe their sexual behaviour with each of their partners in turn. Men were also asked where they had met their sexual partners. A distinction was made between regular partners with whom respondents were currently in a relationship and other non- 
regular partners. Attitudes to condoms were assessed on a five point Likert scale with options for "strongly agree", "agree", "uncertain", "disagree", "strongly disagree". Assessments of respondents' level of knowledge of relevant health risks included the question: "Can you tell me if receptive anal sex without a condom is safe for you to do; assuming you don't know whether your partner is HIV antibody positive or negative?".

The mean age of the sample was 31.6 years (SD 10.4) with a range from 16 to 67 . Eleven per cent of men were either married, separated, divorced or widowed. Fifty one men $(10 \%)$ described their sexual orientation as bisexual, $43(9 \%)$ as homosexual and $392(78 \%)$ as "gay". A further $16(3 \%)$ preferred no designation or unique terms not included in a check list such as "gay transvestite". In terms of education, $63 \%$ had reached higher education (university, polytechnic or higher education college), $23^{\circ}$ o reached some intermediate level of educational qualification and $14 \%$ left school without qualifications and obtained no further education. Using the Registrar General's classification of occupations $84 \%$ were in social classes I, II and III non-manual.

The Mann-Whitney test was used to examine differences on ordinal scales. Otherwise Student's $t$ test or chi square were used as appropriate.

\section{Results}

Seven men $(1 \%)$ reported no sexual partners in the year prior to interview. A further $112(22 \%)$ reported no penetrative anal sex during the same period. Subsequent analyses examine patterns of condom use reported for the previous year by the remaining 383 men $(76 \%)$ all of whom had penetrative anal sex. Regardless of whether men were the insertive or receptive partner in anal sex, they were less likely to use condoms when having sex with a regular compared with a non-regular partner (table 1 ). In order to examine more closely this difference in condom use by type of partner, two groups of men were identified: men having receptive anal sex only with regular partners $(n=150)$ and men having receptive anal sex only with non-regular partners $(n=48)$. Frequency of condom use was not significantly different between the two groups of men. A similar analysis on two sub-groups of men in relation to partner-type and insertive anal sex also failed to obtain statistically significant differences in frequency of condom use. The majority of men $(61 \%)$ had been both insertive and receptive partner in anal sex in the course of the previous year. If condom use for both types of sexual behaviour are combined, $118(31 \%)$ of the 383 men having anal sex reported always using condoms; $171(45 \%)$ were inconsistent users (ie reporting at least one occasion in which condoms were not used) and $94(25 \%)$ never used condoms in anal sex.

Two hundred and forty three men $(48 \%)$ reported having the HIV antibody test, and $30(12 \%$ of those tested) described themselves as HIV positive, 201 $(83 \%)$ as negative and $12(5 \%)$ were awaiting their test.result at the time of interview. Although a higher proportion of the men who were HIV positive compared with men HIV negative always used condoms, the difference was not significant.

Forty four men (9\%) reported penetrative vaginal sex with a regular female partner in the previous year. Only $11 / 44(25 \%)$ reported always using a condom with their regular female partner. Nineteen men (4\%) reported penetrative vaginal sex with a nonregular female partner, of whom $5(26 \%)$ always used a condom with their female partner. Thirty seven men $(7 \%)$ had had both anal sex with a man and vaginal sex with a woman in the previous year. Men having penetrative vaginal sex were no more likely than the rest of the sample to use condoms in anal sex with men.

A majority of men held positive views about the use of condoms in anal sex. Thus 377 men $(75 \%)$ felt that condoms were an acceptable part of sex for them. On the other hand a substantial minority expressed more negative views. Thus $167(33 \%)$ felt that condoms were awkward to use; $117(23 \%)$ felt that they could not enjoy sex if they used a condom; 109 $(22 \%)$ felt that the interruption from having to put on

Table 1 Regularity of condom use amongst men who had anal sex in the last year $(n=383)$

\begin{tabular}{|c|c|c|c|c|}
\hline & \multicolumn{4}{|c|}{ Regularity of condom use $N(\%)$} \\
\hline & Always & Inconsistent & Never & $\begin{array}{l}\text { Number of } \\
\text { men having } \\
\text { this kind } \\
\text { of sex }\end{array}$ \\
\hline $\begin{array}{l}\text { Used in: } \\
\text { Receptive anal sex-regular partners } \\
\text { Receptive anal sex-non-regular partners } \\
\text { Insertive anal sex-regular partners } \\
\text { Insertive anal sex-non-regular partners }\end{array}$ & $\begin{array}{r}107(43 \%) \\
89(60 \%) \\
112(42 \%) \\
93(63 \%)\end{array}$ & $\begin{array}{l}62(25 \%) \\
33(22 \%) \\
64(24 \%) \\
30(20 \%)\end{array}$ & $\begin{array}{l}82(33 \%) \\
27(18 \%) \\
88(33 \%) \\
25(17 \%)\end{array}$ & $\begin{array}{l}251 \\
149 \\
264 \\
148\end{array}$ \\
\hline
\end{tabular}


Table 2 Numbers (\%) of men holding attitudes to condoms in relation to pattern of use of condoms in anal sex in previous year

\begin{tabular}{|c|c|c|c|}
\hline & \multicolumn{3}{|c|}{ Regularity of use of condoms } \\
\hline & $\begin{array}{l}\text { Always } \\
(n=118)\end{array}$ & $\begin{array}{l}\text { Inconsistent } \\
(n=171)\end{array}$ & $\begin{array}{l}\text { Never } \\
(n=94)\end{array}$ \\
\hline $\begin{array}{l}\text { Condoms are now an acceptable part of sex for me } \\
\text { Condoms are awkward and difficult to use } \\
\text { I enjoy sex using a condom } \\
\text { The interruption from putting on a condom puts me off sex } \\
\text { Condoms are not very reliable }\end{array}$ & $\begin{array}{l}111(94 \%) \\
29(25 \%) \\
84(71 \%) \\
16(14 \%) \\
18(15 \%)\end{array}$ & $\begin{array}{r}150(88 \%) \\
61(36 \%) \\
118(69 \%) \\
44(26 \%) \\
37(22 \%)\end{array}$ & $\begin{array}{l}40(43 \%) \\
37(39 \%) \\
40(43 \%) \\
32(34 \%) \\
28(30 \%)\end{array}$ \\
\hline
\end{tabular}

Table 3 Use of condoms and aspects of sexual lifestyles and personal impact of AIDS

\begin{tabular}{llll}
\hline & \multicolumn{2}{l}{ Regularity of use of condoms } \\
\cline { 2 - 4 } & Always & Inconsistent & Never \\
\hline Mean number of partners (SD) previous year & $20 \cdot 2(40 \cdot 6)$ & $23 \cdot 7(49 \cdot 2)$ & $8 \cdot 0(13 \cdot 2)$ \\
Mean number of partners (SD) previous month & $2 \cdot 3(2 \cdot 5)$ & $2 \cdot 5(2 \cdot 4)$ & $1.6(1 \cdot 8)$ \\
$\%$ in closed monogamous relationship & $20 \%(23)$ & $26 \%(44)$ & $45 \%(42)$ \\
$\%$ close friend or partner HIV positive & $41 \%(48)$ & $46 \%(78)$ & $17 \%(16)$ \\
$\%$ close friend or partner died of AIDS & $20 \%(24)$ & $23 \%(39)$ & $10 \%(9)$ \\
\hline
\end{tabular}

a condom put them off sex and $122(24 \%)$ felt that condoms were not very reliable. Attitudes were very closely related to patterns of use, with men who never used condoms always expressing the most negative views (table 2). Men who never used condoms, when compared with consistent and inconsistent users combined, were significantly less likely to view condoms as an acceptable part of $\operatorname{sex}(z=-8 \cdot 88 ; p$ $<0.0001)$; more likely to view condoms as awkward and difficult to use $(z=-3.29 ; p<0.0001)$; more likely to say that the interruption from putting on a condom would put them off sex $(z=-3.52 ; p<$ $0.0005)$; more likely to regard condoms as unreliable $(z=-3 \cdot 16 ; p<0.005)$ and less likely to say that they would enjoy sex using a condom $(z=-4.58 ; p<$ 0.0001 ).

Use of condoms was also related to aspects of sexual lifestyles and personal impact of the AIDS epidemic amongst homosexually active men (table 3 ). Men who never used condoms compared with men who used condoms consistently or inconsistently reported a smaller number of partners in the month prior to interview $(t=-2.92 ; \mathrm{p}<0.005)$ and in the previous year $(t=2.98 ; \mathrm{p}<0.005)$ and were more likely to be in a closed monogamous relationship (chi square 13.23; $p<0.0005$ ). Men never using condoms were less likely to have met sexual partners in the previous year in gay pubs (chi square $7.64 ; p<$ 0.01 ) in gay clubs (chi square 12.06; $p<0.0005$ ) gay saunas (chi square 6.48; $\mathrm{p}<0.05$ ) or in the street (chi square $11.33 ; p<0.005)$. In addition men never using condoms were less likely to know a close friend or partner who was HIV antibody positive (chi square $20.35 ; p<0.0001$ ) or a close friend or partner who had died of AIDS (chi square 6.17; $p<0.05$ ).
Men never using condoms were older than users $(t=$ 2.44; $p<0.05$ ). Educational level, social class, geographical area in which recruited and sexual orientation were not related to condom use.

Involvement in gay social networks and organisations was assessed in a number of different ways. Two hundred and thirty six men $(47 \%)$ reported that more than half of their friends were gay and 281 $\left(56^{\circ}{ }_{0}\right)$ that more than half of their social lives were spent with gay men. Three hundred and twenty five men $\left(65^{\circ}{ }_{0}\right)$ had belonged to a gay organisation and $420\left(84^{\circ}{ }_{0}\right)$ regularly read a gay newspaper or magazine. None of these factors was significantly associated with whether or not individuals used condoms.

The question about receptive anal sex was answered in the negative by 493 men $\left(98^{\circ}{ }_{0}\right)$. There was no association between answers to this question and use of condoms in anal sex.

\section{Discussion}

This survey provides further evidence that use of condoms in penetrative anal sex amongst homosexually active men has increased markedly since earlier in the AIDS epidemic. The proportion of men always using a condom in anal $\operatorname{sex}\left(31^{\circ}{ }_{0}\right)$ is more than twice that obtained $(12 \%)$ from a sample of homosexual and bisexual men attending a London genitourinary medicine clinic during $1984-5 .^{1}$ As has been found in other recent surveys of homosexually active men in Pittsburgh, ${ }^{8}$ Vancouver ${ }^{13}$ and Sydney, ${ }^{14}$ condoms in this sample of men were more likely to be used in non-regular relationships. 
The acceptability of condoms, as assessed by a number of different questionnaire items, was associated with greater use. This is consistent witl other studies that have found favourable attitudes tc condoms predict their greater use amongst homosexually active men. ${ }^{815}$ This is an important finding since such attitudes can continue to be targetted in both clinical and mass health education interventions.

An important component of the HBM involves perceptions of vulnerability and risk. An early study of homosexual sexual behaviour in San Francisco found that knowledge of someone with AIDS was associated with reduced numbers of sexual partners. ${ }^{16}$ Personal awareness of other people with AIDS has also been found to be associated with safer sexual behaviours in Pittsburgh ${ }^{8}$ and Sydney. ${ }^{14}$ In this sample knowing someone very well (as a close friend or partner) who is either HIV antibody positive or who has died of AIDS is associated with greater readiness to use condoms. Awareness of risk may also explain the association between condom use and increased number of sexual partners found in this sample, and in other surveys, ${ }^{817}$ and also our finding that meeting sexual partners at venues such as gay clubs and saunas is also associated with safer sex. In both instances individuals clearly perceive themselves as at greater risk, and use condoms accordingly. Differential perceptions of the degree of risk involved with non-regular compared with regular partners may also account for the differences found in use of condoms and willingness to have penetrative anal sex. ${ }^{618}$ The absence of any strong effect of knowledge of HIV antibody status upon condom use is consistent with other studies of condom use in gay men. ${ }^{8}$ However, a number of methodological difficulties have been identified in observational studies of the impact of the HIV test on behaviour. ${ }^{19}$ One problem in particular with the current study is that no information was gathered about the HIV status of sexual partners.

It is clear that homosexually active men vary considerably in their type and degree of involvement in gay social networks. ${ }^{20}$ Contrary to the predictions of the HBM, involvement in gay social networks, social life and gay organisations was not associated in this study with use of condoms. This result is consistent with evidence from other studies of homosexual men in Sydney, ${ }^{14}$ Chicago, ${ }^{21}$ San Francisco $^{22}$ and New York, ${ }^{23}$ all of which have failed to find a relationship between changes in sexual behaviour and involvement in gay organisations and networks. That gay organisations and social networks played a crucial role in the initial dissemination of information about AIDS prior to mass media health education campaigns cannot be doubted. At this stage of the epidemic, however, their role may be less significant at a behavioural level. It is in any case encouraging that awareness about AIDS and sexual behavioural changes have not been confined to particular sub groups of the population of homosexually active men.

The question assessing mens' awareness of the riskiness of unprotected anal sex was answered correctly by the vast majority of men, as indeed were most other questions about HIV-related knowledge (not discussed in this paper). This is consistent with the results of all previous surveys which have found gay men to be particularly knowledgeable about AIDS. ${ }^{24}$ Discrepancies between knowledge and behaviour are commonly reported not only in studies of homosexual sexual behaviour but in most other kinds of health behaviour. ${ }^{1024}$ The implications of such findings are that information is necessary but not sufficient to induce behavioural change. Other factors may be important such as perceptions of the threat posed by AIDS and attitudes regarding costs and benefits of change.

The financial suppport of the Medical Research Council for this study is gratefully acknowledged.

Address for correspondence: Dr R Fitzpatrick, Nuffield College, Oxford, OX1 1NF, UK.

1 Carne C, Weller I, Johnson A, et al. Prevalence of antibodies to human immunodeficiency virus, gonorrhoea rates, and changed sexual behaviour in homosexual men in London. Lancet 1987;i:656-8.

2 Evans B, McLean K, Dawson S, et al. Trends in sexual behaviour and risk factors for HIV infection among homosexual men, 1984-7. Br Med J 1989;298:215-8.

3 Loveday C, Pomeroy L. Weller I, et al. Human immunodeficiency viruses in patients attending a sexually transmitted disease clinic in London, 1982-7. Br Med J 1989;298:419-22.

4 Gellan M, Ison C. Declining incidence of gonorrhoea in London: a response to fear of AIDS? Lancet 1986;ii:920.

5 Johnson A, Gill $O$. Evidence for recent changes in sexual behaviour in homosexual men in England and Wales. Phil Trans $R$ Soc London 1989;B325:153-61.

6 Fitzpatrick R, McLean J, Boulton M, et al. Variation in sexual behaviour in gay men. In: Aggleton P, Davies $P$, Hart $G$, eds. AIDS: Individual, Cultural and Policy Dimensions. Lewes: Falmer, 1990:121-32.

7 Fitzpatrick R, Boulton M, Hart G, et al. High risk sexual behaviour and condom use in a sample of homosexual and bisexual men. Health Trends 1989;21:76-9.

8 Valdiserri R, Lyter D, Leviton L, et al. Variables influencing condom use in a cohort of gay and bisexual men. Am J Pub Hlth 1988;78:801-5.

9 Cummings K, Becker $M$, Maile $M$. Bringing the models together: an empirical approach to combining variables used to explain health actions. $J$ Behav Med 1980;3:125-45.

10 Becker M, Joseph J. AIDS and behavioral change to reduce risk: a review. Am J Pub Health 1988;78:394-410.

11 Saltzman S, Stoddard A, McCuker J, et al. Reliability of self reported sexual behaviour risk factors for HIV infection in homosexual men. Public Health Rep 1987;102:692-7.

12 Coates R, Calzavara L, Soskolone C, et al. Validity of sexual histories in a prospective study of male sexual contacts of men with AIDS or an AIDS related condition $A m J$ Epidemiol 1988;128:719-28.

13 Schechter M, Craib K, Willoughby B, et al. Patterns of sexual behavior and condom use in a cohort of homosexual men. $A m J$ Pub Health 1988;78:1535-8.

14 Connell R, Crawford J, Kippax S, et al. Facing the epidemic: changes in the sexual lives of gay and bisexual men in Australia and their implications for AIDS prevention strategies. Social Problems 1989;36:384-401. 
15 Ross M. Attitudes toward condoms as AIDS prophylaxis in homosexual men. Psychology and Health 1988;2:291-9.

16 McKusick L, Horstman W, Coates T. AIDS and sexual behavior report by gay men in San Francisco. Am J Pub Health 1985;75:493-6.

17 van Griensven G, Vroome E, Tielman R, Coutinho R. Failure rate of condoms during anogenital intercourse in homosexual men. Genitourin Med 1988;64:344-6.

18 Fitzpatrick R, Hart G, Boulton M, et al. Heterosexual sexual behaviour in a sample of homosexually active men. Genitourin Med 1989;65:259-62.

19 Cates W, Handsfield H. HIV counseling and testing: does it work? Am J Pub Health 1988;78:1533-4.

20 Hart G, Fitzpatrick R, McLean J, et al. Gay men, social support and HIV disease: a study of social integration in the gay community. AIDS Care, (in press).

21 Joseph J, Montgomery S, Emmons C, et al. Magnitude and determinants of behavioral risk reduction: longitudinal analysis of a cohort at risk for AIDS. Psychology and Health 1987;1:73-96.

22 McKusick L, Coates T, Wiley J, et al. Prevention of HIV infection among gay and bisexual men: two longitudinal studies. Third International Conference on AIDS, Abstracts, Washington, DC, 1987.

23 Siegel K, Mesagno F, Chen J, Christ G. Factors distinguishing homosexual males practising risky and safer sex. Soc Sci Med 1989;28:561-9.

24 Fitzpatrick R, Boulton M, Hart G. Gay men's sexual behavior in response to AIDS-insights and problems In: Aggleton $P$, Hart G, Davies P, eds. AIDS: Social Representations, Social Practices. Lewes, Falmer 1989:126-46.

Accepted for publication 19 June 1990 